\title{
Evaluation of the Scandinavian guidelines for head injuries based on a consecutive series with computed tomography from a Norwegian university hospital
}

Ingrid Haavde Strand ${ }^{1 \dagger}$, Ole Solheim ${ }^{2,3^{*}+}$, Kent Gøran Moen ${ }^{2,4}$ and Anne Vik ${ }^{2,4}$

\begin{abstract}
Background: This study prospectively assesses clinical characteristics and management of consecutive minimal, mild and moderate head injury patients referred for CT scans. Compliance with the Scandinavian head injury guidelines and possible reasons for non-compliance is explored.

Methods: From January $16^{\text {th }} 2006$ to January $15^{\text {th }} 2007,1325$ computed tomography (CT) examinations due to minimal, mild or moderate head injury according to the Head Injury Severity Scale (HISS) were carried out at our University Hospital. When ordering a CT scan due to head trauma, physicians were asked to fill out a questionnaire.

Results: Guideline compliance was impossible to assess in $49.5 \%$ of all cases. This was due to non-assessable or missing key variables necessary in the decision making algorithm. One or more key variables for HISS classification were not assessable in $34.4 \%$ as it was unknown whether there had been loss of consciousness (LOC), duration of LOC was unknown or it was impossible to assess amnesia or focal neurologic deficits. Definite compliance with both $C T$ and admittance recommendations in guidelines was seen in only $31.2 \%$. In $54.2 \%$ of patients with minimal head injuries who underwent $C T$ scans, imaging was not necessary according to guidelines. $59.1 \%$ of all patients were admitted to hospital, however only $23.7 \%$ of these were admitted because of the head-injury alone. Age $<4$ years, possible medical cause of injuries, severe headache/nausea or vomiting and the presence of non-traumatic CT findings were independently associated with non-assessable compliance with Scandinavian guidelines. Suspicion of influence of alcohol was inversely associated to non-compliance.
\end{abstract}

Conclusions: Despite the prospective study design, guideline compliance was not assessable in nearly half of the patients. Patients with isolated head injuries and available and obtainable complete clinical information necessary for guideline-based decision making are not dominating in a head injury population.

Keywords: CT scan, Guideline compliance, Minor head injury, Traumatic brain injury

\section{Background}

Guidelines for the initial management of minimal, mild or moderate head injuries [1-5] were implemented approximately a decade ago. They provide evidence based algorithms for decision making, including indications for $\mathrm{CT}$

\footnotetext{
* Correspondence: ole.solheim@ntnu.no

${ }^{\dagger}$ Equal contributors

${ }^{2}$ Department of Neurosurgery, St.Olavs University Hospital, Trondheim N-7006, Norway

${ }^{3}$ MI-Lab, Department of Circulation and Medical Imaging, Norwegian University of Science and Technology, Trondheim N-7006, Norway Full list of author information is available at the end of the article
}

examinations, admission for observation or discharge in patients with head injuries. The decision trees vary some but are all based on combinations of a set of clinical and anamnestic factors, such as the Glasgow Coma Scale (GCS) score on arrival, loss of consciousness (LOC), amnesia, vomiting, headache, focal neurologic deficits, intoxication, suspected skull fracture, seizures, dangerous trauma mechanisms, failure to improve, coagulopathy, and/or prior neurosurgery. Sensitivity of detection of patients requiring neurosurgical interventions is for most guidelines close to $100 \%$, but specificity is much lower [6].

\section{Biomed Central}


Patient management can be affected by numerous factors not taken into consideration in the guidelines, including the distance to hospital, patient co-morbidities and other injuries, limitation of radiology services, availability of hospital beds, patient demands, severity of pain, language barriers, the ability to be observed at home and local transportation logistics. Also, anamnestic and clinical information necessary for guideline based decision making may be unavailable when deciding to order CTs, discharge, or admit for observation. Thus, while guidelines can provide good support for clinical decisions, decision rules are sometimes not directly applicable and not always followed.

Head injury guideline compliance has been sparsely studied [7-9]. A retrospective study from 2003, two years after the implementation of the Scandinavian guidelines, found that overall compliance was only $51 \%$, and that over triage was seen in $69 \%$ of patients with minimal injuries. However, since many of the important patients' characteristics were unavailable, reasons for non-compliance could not be explored [10].

We conducted a prospective study based on all CTexaminations for minimal, mild and moderate head injuries in a one year period in a Norwegian university hospital. We aimed to assess clinical characteristics, management and compliance with Scandinavian guidelines and explore possible reasons for non-compliance.

\section{Methods}

\section{The study setting and patient referral}

St.Olavs Hospital, University Hospital of Trondheim, Norway is a level I trauma centre for 680,000 inhabitants and houses the only neurosurgical department in the region and hence receives all severe and many moderate head injuries from three counties. Additionally, the hospital serves as a local hospital for 275,000 inhabitants. Many minimal and mild head injuries are initially managed by general practitioners either at their offices during day-time, at regional emergency clinics, or on call in the emergency clinic at the hospital. Some patients are referred to the neurosurgical resident on call, before or after CT examinations. Other suspected head injuries are managed directly by resident neurosurgeons, typically patients transported directly by ambulance or helicopter from site of injury. Further, some head injuries are initially managed by the hospital trauma team, when there is suspected or confirmed multi-trauma or high energy trauma, according to the advanced trauma life support (ATLS) guidelines. Additionally, some head injuries may be referred by or admitted to various hospital departments as part of more complex medical settings, e.g. syncope, seizure, intoxication or possible stroke followed by head injury.

\section{The implementation of guidelines and information about the study}

The Scandinavian guidelines [5] were implemented after a national campaign in 2000, and the decision algorithm is based on the Head Injury Severity Scale (HISS) [11] and the presence of additional risk factors (Figure 1). Prior to and at the beginning of the inclusion period, the first author (IHS) reminded the various in-hospital departments involved (neurosurgical, ENT, neurology, internal medicine, surgical departments, general practitioners' emergency clinic and radiology department) about the Scandinavian guidelines and informed about the prospective study protocol and its questionnaire.

\section{The inclusion process}

During the one-year period from January $16^{\text {th }} 2006$ to January $15^{\text {th }} 2007,1446$ primary CT scans due to head trauma or multi-trauma were carried out (Figure 2). After exclusion of assumed severe head injuries and CTs due to head trauma that was more than 7 days ago, 1325 primary CTs of patients with recent minimal, mild or moderate head injuries were included in the present study. 396 (30\%) of the CT scans were ordered by general practitioners at the emergency clinic in the hospital, $317(24 \%)$ were requested by the hospital trauma team due to suspected or confirmed multi-trauma or high energy trauma,187 (14\%) were ordered by resident neurosurgeons, 33 (3\%) by surgeons from other departments, $216(16 \%)$ by other hospital specialists, and $176(13 \%)$ by general practitioners outside the hospital.

\section{The questionnaire and study variables}

When ordering head CT examinations due to trauma, in-hospital physicians were asked to fill out a questionnaire. The primary response was 708/1152 (62\%), but increased to $984(85 \%)$ after a reminder. In addition to the 169 missing questionnaires from in-hospital physicians, questionnaire based data was missing from 173 CT examinations ordered by general practitioners not working in the hospital, thus unaware of the study and its questionnaire. In cases with missing or incomplete questionnaires we (IHS) attempted to retrieve missing variables from hospital medical records and radiology order forms. However, in many cases it was impossible to obtain key variables through this retrospective review, and such variables are categorized as missing. If data was not obtainable due to the patient's condition or lack of reliable witnesses, some questionnaire items were prospectively reported or retrospectively classified as unknown or not possible to assess. Patient management was classified as either compliant with guidelines, noncompliant with guidelines or impossible to assess according to this point-by-point list: 


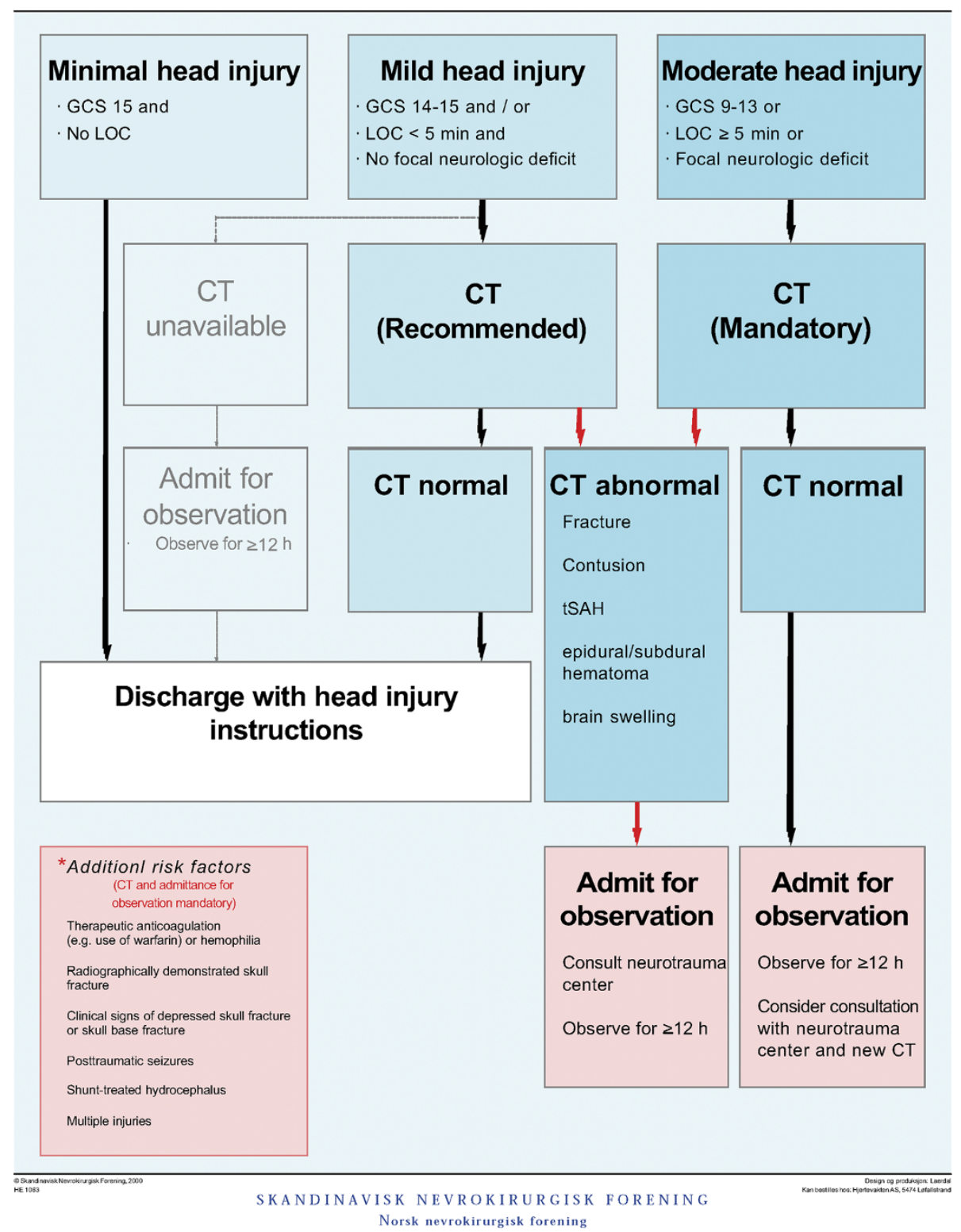

Figure 1 Decision-making algorithm by the Scandinavian Neurotrauma Committee. The figure shows the Scandinavian decision-making algorithm for the management of minimal, mild and moderate head injuries.

- Compliant (y/n)

- Isolated minimal, mild or moderate head injury managed according to guidelines

- Non-compliant $(\mathrm{y} / \mathrm{n})$

- Minimal head injury, no additional risk factors, but CT performed

- Isolated mild head injury, normal CT, no risk factors and admittance to hospital

- Moderate head injury without admittance to hospital $\circ$ Minimal or mild injury, risk factors, without admittance to hospital

- Mild head injury within the last $12 \mathrm{~h}$, normal CT, living alone, without admission to hospital

- Minimal or mild head injury within the last 12 hours, traumatic CT findings but not admittance to hospital

- Impossible to assess $(\mathrm{y} / \mathrm{n})$

- Admittance due to other injuries or medical causes

- Unknown/Non-assessable key-variables

$\circ$ Missing data 


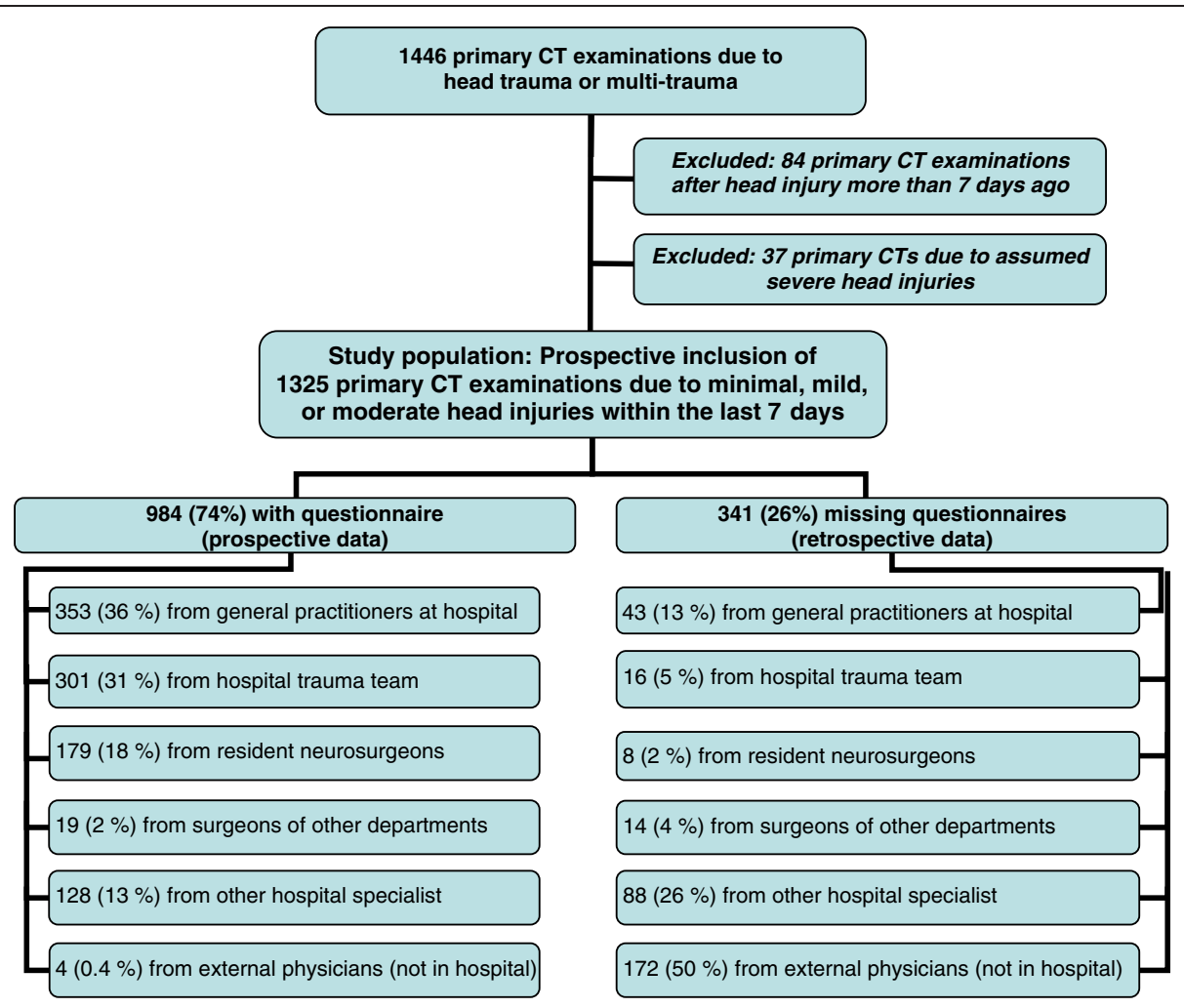

Figure 2 The inclusion and exclusion process. The inclusion and exclusion process leading to a study population of 1325 primary CT examinations after recent minimal, mild, or moderate head trauma is shown.

\section{Time of assessment}

Since aiming to investigate guideline compliance, only the situation prior to ordering the CT examination was assessed. Thus, classification into to the HISS categories and other clinical variables reflects the last known status before ordering CT examinations. Likewise, when reviewing patient hospital records, we attempted to explore the situation prior to ordering the CT. Radiology reports in $43(3.2 \%)$ of the CT examinations were later changed, but we utilized the initial image descriptions in the present study, since these formed basis for clinical decisions at the time.

\section{Statistics}

Data was analyzed in SPSS version 19 for Windows. QQ-plots were used to test for normal distribution. Central tendencies are presented as medians when skewed. Mann-Whitney-U test was used for significance testing in ordinal data with skewed distributions. Chi-square test was used for significance testing in contingency tables and Fisher's exact test was used where sample sizes were less than 5. Binary regression analyses were performed, and predictor variables with p-values less than 0.1 were included in multivariable regression models. Statistical significance level was set to $\mathrm{p}<0.05$.

\section{Ethics}

The study was approved by the Regional Ethical Committee for Health Region Mid-Norway and the Norwegian Social Science Data Services. Inclusion of patient data without informed consent was approved by the Norwegian Directorate of Health.

\section{Results}

\section{General characteristics and classification according} to HISS

Age, sex, injury mechanism and time of CT for the 1325 patients are presented in Table 1 . While $1.8 \%$ were infants/toddlers, $22.6 \%$ were elderly ( $\geq 65$ years).

We were unable to classify $365(27.5 \%)$ of the included patients according to the HISS-criteria, either due to non-assessable key-variables or missing keyvariables. Questionnaires were missing in 237 (64.9\%) of these, most often when CT orders were placed by general practitioners outside the hospital. To explore the possibility of imputation of missing variables, we compared patients who were classifiable according to the HISS criteria with non-classified patients (Table 2). The two groups differed significantly for all tested variables. Imputation of missing variables was therefore not performed. 


\begin{tabular}{|c|c|}
\hline General characteristics & $N=1325$ \\
\hline \multicolumn{2}{|l|}{ Gender } \\
\hline Male & $754(56.9 \%)$ \\
\hline \multicolumn{2}{|l|}{ Age } \\
\hline Median [Range] & 35 [0-100] \\
\hline Infant/toddler (0-3) & $24(1.8)$ \\
\hline Children (4-15) & $169(12.8 \%)$ \\
\hline Adolescents/young adults (16-20) & $160(12.1 \%)$ \\
\hline Adults (21-64) & $673(50.8 \%)$ \\
\hline Elderly ( $\geq 65)$ & $299(22.6 \%)$ \\
\hline \multicolumn{2}{|l|}{ Trauma mechanism } \\
\hline Falls & $688(51.9 \%)$ \\
\hline Traffic accidents & $349(26.3 \%)$ \\
\hline Violent assaults & $107(8.1 \%)$ \\
\hline Other* & $140(10.6 \%)$ \\
\hline Unknown/missing data & $41(3.1 \%)$ \\
\hline \multicolumn{2}{|l|}{ Time from trauma to CT scan } \\
\hline Median & 2.6 hours \\
\hline$<12$ hours & $785(59.2 \%)$ \\
\hline$>12$ hours & $94(7.1 \%)$ \\
\hline Unknown/missing data & $446(33.7 \%)$ \\
\hline \multicolumn{2}{|l|}{ Time of CT scan } \\
\hline Weekday (Mon-Fri, 08-15) & $343(25.9 \%)$ \\
\hline Weekday evening (Mon-Fri 15-22) & $288(21.7 \%)$ \\
\hline Weekday night (Mon-Thu 22-08) & $143(10.8 \%)$ \\
\hline Weekend/Holiday (Fri -Mon 15-08) & $551(41.6 \%)$ \\
\hline
\end{tabular}

*Includes head traumas without falling or violence and/or possible medical cause of trauma (e.g. syncope, epilepsy, cardiac arrest etc.).

\section{Non-assessable or unknown key variables for HISS classification}

At presentation, one or more variables potentially crucial for HISS classification were frequently unknown or nonassessable due to the patients' condition or lack of witness observations (Table 3). In 456 (34.4\%) of all 1325 patients, $382(83.8 \%)$ of whom had available questionnaire data, either GCS score was non-assessable (intubation), the presence or the duration of LOC was either unknown or not assessable, it was not possible to assess if the patient had posttraumatic amnesia, or it was not possible to assess if the patient had focal neurologic deficits. Both infants/toddlers $(<4$ years $)$ and elderly $(\geq 65$ years $)$ were significantly $(\mathrm{p}<0.001)$ more seldom classifiable into HISS categories, despite available questionnaires. Assumed focal neurologic deficits before the CT examination were reported in $12.6 \%$ of elderly patients ( $\geq 65$ years), as compared to $4.0 \%$ of the younger patients $(\mathrm{p}<0.001)$.
Additional risk factors from the Scandinavian guidelines Before the CT examination, 28.2\% of all patients had one or more "additional risk factors" according to the decision algorithm (Figure 1, Table 4). If including patients with later radiological diagnosed cranial fracture, this percentage increases to $29.5 \%$.

Severe headache, nausea or vomiting was observed in $27.8 \%$, a clinical suspicion of alcohol or drug intoxication was reported in $17.4 \%$ and at least $15.4 \%$ of all patients were living alone.

\section{CT findings and management after CT examination}

As seen in Table 5, intracranial traumatic CT findings were primarily described in $6.3 \%$ and cranial fractures in $2.9 \%$. Non-traumatic pathological findings were described in $20.2 \%$. Only $0.9 \%$ of the 1325 patients underwent a neurosurgical intervention, most often patients with moderate head injuries.

789 (59.5\%) of the 1325 who underwent CT scans were admitted to hospital. Among patients who were admitted, combined causes were most common (47.3\%). Only $186(23.6 \%)$ of admitted patients were admitted because of head injury alone.

\section{Compliance with Scandinavian guidelines}

Overall compliance with guidelines was impossible to assess in $49.5 \%$ of all 1325 cases (Table 6). This was due to non-assessable or missing key variables for HISS classification or patients who were admitted due to other injuries/other medical causes, or when it was unknown if patients were living alone. Non-compliance was seen in $19.3 \%$, either due to unnecessary CT scans (11.2\%), violation of the admission recommendations, or both. Thus, definite compliance with the Scandinavian guidelines was seen in $31.2 \%$. However, overall compliance was $61.7 \%$ for the 669 assessable patients. $54.2 \%$ of patients with minimal head injuries had overtriage with CT scans.

\section{Predictors of non-assessable compliance with CT guidelines (i.e. when are guidelines difficult to apply?)}

Age $<4$ years, possible medical cause of injuries, severe headache/nausea or vomiting, and the presence of nontraumatic CT findings were independently associated with non-assessable compliance in the multivariable analyses (Table 7). Use of antiplatelet drugs tended also to be an independent predictor.

\section{Predictors of non-compliance with guidelines}

Suspicion of influence by alcohol or drugs was inversely associated with non-compliance with guidelines (O.R. $0.4, \mathrm{p}=0.003$ ). There was also a trend towards a positive association with severe nausea/headache or vomiting $(\mathrm{p}=0.100)$. Neither gender, toddlers (age $<4)$, elderly (age $\geq 65$ ), trauma mechanism, clinical affiliation of CT 
Table 2 Comparison of patients with missing or non-assessable variables for HISS classification and patients with complete data

\begin{tabular}{|c|c|c|c|}
\hline Characteristics & Classified according to HISS N=960 & Not classified according to HISS N= 365 & p-values \\
\hline \multicolumn{4}{|l|}{ Questionnaire responders } \\
\hline Yes & $855(89.1 \%)$ & $128(35.1 \%)$ & $<0.001$ \\
\hline \multicolumn{4}{|l|}{ Time of CT examination } \\
\hline Weekend/Holiday & $446(46.5 \%)$ & $105(28.2 \%)$ & $<0.001$ \\
\hline \multicolumn{4}{|l|}{ Trauma mechanism } \\
\hline Injury while being hospitalized & $5(0.5 \%)$ & $29(8.0 \%)$ & $<0.001$ \\
\hline Male & $581(60.5 \%)$ & $173(47.4 \%)$ & $<0.001$ \\
\hline \multicolumn{4}{|l|}{ Age } \\
\hline Median & 30 years & 52 years & $<0.001$ \\
\hline Clinical affiliation of $\mathrm{CT}$ ordering doctor & & & $<0.001$ \\
\hline GP emergency clinic (in hospital) & $322(33.5 \%)$ & $74(20.3 \%)$ & \\
\hline Neurosurgical department & $167(17.4 \%)$ & $20(5.5 \%)$ & \\
\hline Other hospital department & $102(10.6 \%)$ & $147(40.3 \%)$ & $<0.001$ \\
\hline Trauma team & $309(32.2 \%)$ & $8(2.2 \%)$ & \\
\hline External GP (not in hospital) & $60(6.3 \%)$ & $116(31.8 \%)$ & \\
\hline \multicolumn{4}{|l|}{ CT findings } \\
\hline Traumatic findings (\%) & $91(9.5 \%)$ & $12(3.3 \%)$ & $<0.001$ \\
\hline \multicolumn{4}{|l|}{ Admittance to hospital? } \\
\hline Yes & $593(61.8 \%)$ & $196(53.7)$ & 0.007 \\
\hline \multicolumn{4}{|l|}{ Neurosurgical intervention? } \\
\hline Yes & $12(1.3 \%)$ & $0(0 \%)$ & 0.027 \\
\hline
\end{tabular}

ordering physician, CT-examination at night (22:3008:00), non-traumatic CT findings, posttraumatic amnesia, living alone, nor physical signs of head injury were associated with non-compliance with guidelines in univariable analyses.

\section{Sensitivity of Scandinavian guidelines}

One 72 year old patient with minimal head injury after a fall from own height and no risk factors who underwent a CT examination after 95 minutes, non-compliant to guidelines, deteriorated in the CT lab and underwent surgery due to an acute subdural hematoma $(60 \mathrm{ml})$. Thus, the sensitivity for detecting lesions of neurosurgical significance was 11/12 (92\%) (Table 5). Twelve of the 103 patients with traumatic CT findings underwent overtriage with $\mathrm{CT}$, according to the Scandinavian guidelines, while compliance with CT guidelines was impossible to assess in another 10 patients with traumatic findings. Sensitivity for detecting any traumatic finding based on the Scandinavian guidelines may therefore be estimated to be between $78 \%$ and $88 \%$.

\section{Discussion}

In this large study in patients assumed to have minimal, mild and moderate head injuries before CT examinations, there was much heterogeneity in terms of patient characteristics, co-morbidity, and health care management. Despite the prospective study design in a university hospital setting, definite compliance with guidelines was observed in only one third of the patients. More striking; for nearly half of the patients, compliance was not assessable. Key factors in the guideline decision algorithm were frequently simply not obstainable, including the presence and duration of LOC, posttraumatic amnesia and focal neurological deficits. It was further observed that admission due to the head injury alone was accounting for only one quarter of the hospital admissions. This reflects a limitation in the direct applicability of decision guidelines in many patients referred for CT scans due to head injuries.

\section{Compliance with Scandinavian guidelines}

In Norway and other countries where emergency medicine is not defined as an own specialty with separate departments, head injuries are primarily managed by a range of departments and specialists, including general practitioners outside the hospital, perhaps increasing the difficulty of enforcing guidelines. We found that $11.2 \%$ of CT scans, more than half in patients with minimal head injuries, were unnecessary, while one fifth were 
Table 3 Reported clinical findings and symptoms important for HISS classification at the clinical examination before CT

\begin{tabular}{|c|c|c|c|c|c|}
\hline \multirow[t]{2}{*}{$\begin{array}{l}\text { Clinical findings and symptoms } \\
\text { at presentation }\end{array}$} & \multirow{2}{*}{$\begin{array}{l}\text { Minimal injury } \\
\mathrm{N}=275\end{array}$} & \multirow{2}{*}{$\begin{array}{l}\text { Mild injury } \\
\mathrm{N}=525\end{array}$} & \multirow{2}{*}{$\begin{array}{l}\text { Moderate injury } \\
\mathrm{N}=160\end{array}$} & \multirow{2}{*}{$\begin{array}{l}\text { Missing data or } \\
\text { not classifiable } \\
\mathrm{N}=365\end{array}$} & \multirow{2}{*}{$\begin{array}{l}\text { Overall } \\
\mathrm{N}=1325\end{array}$} \\
\hline & & & & & \\
\hline \multicolumn{6}{|l|}{ Glasgow Coma Scale score } \\
\hline 15 & $271(98.5 \%)$ & $379(72.2 \%)$ & $64(40.0 \%)$ & $129(35.3 \%)$ & $843(63.6 \%)$ \\
\hline 14 & N/A & $140(26.7 \%)$ & $15(9.4 \%)$ & $24(6.6 \%)$ & $179(13.5 \%)$ \\
\hline $9-13$ & N/A & N/A & $68(42.5 \%)$ & $13(3.6 \%)$ & $81(6.1 \%)$ \\
\hline Intubated/sedated & $2(0.7 \%)$ & $2(0.4 \%)$ & $7(4.4 \%)$ & $4(1.1 \%)$ & $15(1.1 \%)$ \\
\hline Missing data & $2(0.7 \%)$ & $4(0.8 \%)$ & $6(3.8 \%)$ & 195 (53.4\%) & $207(15.6 \%)$ \\
\hline \multicolumn{6}{|l|}{ Loss of consciousness (LOC)? } \\
\hline No & $236(85.8 \%)$ & $64(12.2 \%)$ & $28(17.5 \%)$ & $69(18.9 \%)$ & $397(30.0 \%)$ \\
\hline Yes & N/A & $306(58.3 \%)$ & $70(43.8 \%)$ & $122(33.4 \%)$ & $499(37.7 \%)$ \\
\hline$<5$ minutes & N/A & $243(46.3 \%)$ & $23(14.4 \%)$ & $62(17.0 \%)$ & $329(24.8 \%)$ \\
\hline$\geq 5$ minutes & N/A & $\mathrm{N} / \mathrm{A}$ & $38(23.8 \%)$ & $15(4.1 \%)$ & $56(4.2 \%)$ \\
\hline Unknown length of $L O C \Omega$ & N/A & $63(12.0 \%)$ & $9(5.6 \%)$ & $45(12.3 \%)$ & $114(8.6 \%)$ \\
\hline Unknown if $L O C \Omega$ & $35(12.7 \%)$ & $148(28.2 \%)$ & $39(24.4 \%)$ & $58(15.9 \%)$ & $280(21.1 \%)$ \\
\hline Missing data & $4(1.5 \%)$ & $7(1.3 \%)$ & $23(14.4 \%)$ & $116(31.8 \%)$ & $149(11.2 \%)$ \\
\hline \multicolumn{6}{|l|}{ Posttraumatic amnesia? } \\
\hline No, n (\%) & $254(92.4 \%)$ & $99(18.9 \%)$ & $33(20.6 \%)$ & $66(18.1 \%)$ & $452(34.1 \%)$ \\
\hline Yes, n (\%) & $0(0 \%)$ & $394(75.1 \%)$ & $62(38.8 \%)$ & $98(26.8 \%)$ & $555(41.9 \%)$ \\
\hline Impossible to assess & $16(5.8 \%)$ & $22(0.4 \%)$ & $32(20.0 \%)$ & $38(10.4 \%)$ & $107(8.1 \%)$ \\
\hline Missing data & $5(1.8 \%)$ & $10(1.9 \%)$ & $33(20.6 \%)$ & $163(44.7 \%)$ & $211(15.9 \%)$ \\
\hline \multicolumn{6}{|l|}{ Assumed focal neurologic deficits? } \\
\hline No & $260(94.5 \%)$ & $492(93.7 \%)$ & $73(45.6 \%)$ & $256(70.1 \%)$ & $1081(81.6 \%)$ \\
\hline Yes & $0(0 \%)$ & $0(0 \%)$ & $57(35.6 \%)$ & $10(2.7 \%)$ & $67(5.1 \%)$ \\
\hline Impossible to assess & $6(2.2 \%)$ & $18(3.4 \%)$ & $17(10.6 \%)$ & $18(4.9 \%)$ & $59(4.5 \%)$ \\
\hline Missing data & $9(3.3 \%)$ & 15 (2.9\%) & $13(8.1 \%)$ & $81(22.2 \%)$ & 118 (8.9\%) \\
\hline
\end{tabular}

$\Omega$ Loss of consciousness, or duration was impossible to assess due to lack of witnesses and uncertain anamnestic information.

either admitted to hospital or discharged in contradiction to the recommendations in the Scandinavian guidelines. Definite compliance with guidelines was therefore only observed in one third of all patients. Among assessable patients, overall guideline compliance was $61.7 \%$. In comparison, two other studies have reported the overall compliance with Scandinavian guidelines to be $51 \%$ and $60.5 \%$, respectively $[7,12]$. A recent study demonstrated an almost perfect compliance for adults requiring head $\mathrm{CT}$ according to the NICE guidelines, but a much lower compliance in children [9]. However, oddly compliance was always assessable in these studies, even retrospectively $[7,9,12]$.

\section{Predictors of non-compliance}

We found that guidelines seemed more difficult to apply in toddlers, patients with medical causes of injuries, severe nausea/headache or vomiting or presence of nontraumatic CT findings. These findings are not surprising and are clinical factors not covered in the Scandinavian guidelines. Headache and/or vomiting are, however, symptoms included in the decision algorithm of several other guidelines $[1,3,9]$.

Also, we found that compliance may be better when there is suspicion of influence by alcohol or drugs, whereas the other studied factors were not predictors for non-compliance. In contrast, a recent retrospective study reported that physicians' guideline compliance is not affected by the patients' alcohol consumption [12]

\section{The co-morbidity of head injuries}

The co-morbidity of head injuries and the fact that they often also occur in more complex medical settings, can make it difficult to directly apply guidelines in many cases. Barely a fourth of the admitted patients were admitted due to the head injury alone. Thus, isolated minimal or mild head injuries in patients without other injuries or diseases, not living alone, are perhaps more seldom than expected. The presence of possible "additional risk factors" (as defined by the guidelines) when 
Table 4 Reported risk factors and other variables important for decision making according to Scandinavian guidelines

\begin{tabular}{|c|c|c|c|c|c|}
\hline \multirow[t]{2}{*}{$\begin{array}{l}\text { Risk factors and other clinical findings } \\
\text { and symptoms }\end{array}$} & \multirow{2}{*}{$\begin{array}{l}\text { Minimal injury } \\
\mathrm{N}=\mathbf{2 7 5}\end{array}$} & \multirow{2}{*}{$\begin{array}{l}\text { Mild injury } \\
\mathrm{N}=525\end{array}$} & \multirow{2}{*}{$\begin{array}{l}\text { Moderate injury } \\
\mathrm{N}=160\end{array}$} & \multirow{2}{*}{$\begin{array}{l}\text { Missing data or } \\
\text { not classifiable } \\
\mathrm{N}=365\end{array}$} & \multirow{2}{*}{$\begin{array}{l}\text { Overall } \\
\mathrm{N}=1325\end{array}$} \\
\hline & & & & & \\
\hline \multicolumn{6}{|c|}{ Risk factors from the Scandinavian Guidelines $\Omega$} \\
\hline - Therapeutic anticoagulation or hemophilia & $12(4.4)$ & $12(2.3 \%)$ & $7(4.4 \%)$ & $26(7.1 \%)$ & $57(4.3 \%)$ \\
\hline $\begin{array}{l}\text { - Clinical suspicion of impression fracture or } \\
\text { skull base fracture }\end{array}$ & $10(3.6 \%)$ & $23(4.4 \%)$ & $8(5.0 \%)$ & $13(3.6 \%)$ & $54(4.1 \%)$ \\
\hline . Posttraumatic epileptic seizure & $1(0.4 \%)$ & $5(1.0 \%)$ & $5(3.1 \%)$ & $5(1.4 \%)$ & $16(1.2 \%)$ \\
\hline - Shunt due to hydrocephalus & $1(0.4 \%)$ & $1(0.2 \%)$ & $1(0.6 \%)$ & $0(0 \%)$ & $3(0.2 \%)$ \\
\hline - Multi-traumatized patient \# & $112(40.7 \%)$ & $105(20.0 \%)$ & $42(26.3 \%)$ & $9(2.5 \%)$ & $268(20.2 \%)$ \\
\hline \multicolumn{6}{|l|}{ Additional patient characteristics } \\
\hline - Severe headache, nausea or vomiting & $61(22.2 \%)$ & $168(32.0 \%)$ & $25(15.6 \%)$ & $114(31.2 \%)$ & $368(27.8 \%)$ \\
\hline - Use of anti-platelet drugs & $17(6.2 \%)$ & $20(3.8 \%)$ & $20(12.5 \%)$ & $51(14.0 \%)$ & $108(8.2 \%)$ \\
\hline \multicolumn{6}{|l|}{ - Living alone } \\
\hline Yes & $32(11.6 \%)$ & $73(13.9 \%)$ & $33(20.6 \%)$ & $66(18.1 \%)$ & $204(15.4 \%)$ \\
\hline Missing data & $4(1.5 \%)$ & $8(1.5 \%)$ & $11(6.9 \%)$ & $79(21.6 \%)$ & $102(7.7 \%)$ \\
\hline \multicolumn{6}{|c|}{ Clinical suspicion of alcohol/drug intoxication at presentation } \\
\hline$\cdot$ No & $209(76.0 \%)$ & $354(67.4 \%)$ & $92(57.5 \%)$ & $121(33.2 \%)$ & $776(58.6 \%)$ \\
\hline - Yes & $27(9.8 \%)$ & $128(24.4 \%)$ & $50(31.3 \%)$ & $25(6.9 \%)$ & $230(17.4 \%)$ \\
\hline . Unknown/missing data & 39 (14.2\%) & $43(8.2 \%)$ & $18(11.3 \%)$ & 219 (60.0\%) & 319 (24.1\%) \\
\hline
\end{tabular}

$\Omega$ Radiological cranial fracture is also an additional risk factor.

\# Questionnaire marked for multi-traumatized patient or CT of multiple organs ordered by hospital trauma team (trauma CT), or multiple radiological examinations of different organs ordered by treating physicians.

examining the patient in the ER, was frequent (28.2\%), and since at least $15.4 \%$ lived alone, observation at home and the recommended nightly wake-up-checks are also sometimes problematic. We observed that presentation with assumed focal neurologic deficits and thereby a possible moderate head injury, was reported significantly more often in the elderly, perhaps illustrating possible assessment difficulties if there is neurologic comorbidity or even normal aging.

\section{Sensitivity of guidelines}

As only $0.9 \%$ underwent brain or skull surgery after CT examination; $0.3 \%$ if excluding the moderate injuries, outcome is usually good, often regardless of compliance with management guidelines. Also to be remembered, guidelines are not perfect and clinical judgment is still necessary. We found a sensitivity of $92 \%$ for detection of findings in need of surgery. Although the Scandinavian guidelines perform quite well in comparison with other guidelines [13], a recent systematic review concluded that the Canadian CT Head Rule is more widely validated and has demonstrated the most consistent results [6]. Still to be remembered, although guidelines seem to perform quite well in various validation studies [14], everyday practice may be different. The inclusion and exclusion criteria of studies behind the guidelines and their respective validation studies may affect external validity of results. For example, in a recent validation study of 6936 head injury patients, only $52 \%$ met the study inclusion criteria [14]. This potentially affects the generalizability of results to everyday settings. Imputation of missing variables or conducting complete data analyses, as often seen in the decision rule literature, seems dubious due to significant differences between groups as demonstrated in our study.

\section{Unnecessary CT scans and impact on health economics}

In the pre-guideline era, some authors recommended routine $\mathrm{CT}$ as a screening tool, with selective admission being based on CT findings [8,15-18], while others recommended routine admission with or without CT scanning $[19,20]$. Also, there used to be considerable inter-hospital variations in patient management $[21,22]$. A controlled study reported that early CT and discharge is cheaper and at least as effective as hospital admission in mild injuries [23]. Liberal use of CT scanning based on a high sensitivity decision rule may therefore be both effective and cost-saving, since the cost of CT scanning is small compared to costs of caring for patients with head injury worsened by delayed treatment [24]. Still, unnecessary CT examinations should be avoided both to save health personnel resources and avoid unnecessary radiation, concerns and morbidification. Head injury guidelines can theoretically reduce 
Table 5 CT image findings (initial description) and patient management

\begin{tabular}{|c|c|c|c|c|c|}
\hline \multirow[t]{2}{*}{$\begin{array}{l}\mathrm{CT} \text { findings and management } \\
\text { after } \mathrm{CT} \text { examination }\end{array}$} & \multirow{2}{*}{$\begin{array}{l}\text { Minimal injury } \\
\mathrm{N}=275\end{array}$} & \multirow{2}{*}{$\begin{array}{l}\text { Mild injury } \\
\mathrm{N}=525\end{array}$} & \multirow{2}{*}{$\begin{array}{l}\text { Moderate injury } \\
\mathrm{N}=160\end{array}$} & \multirow{2}{*}{$\begin{array}{l}\begin{array}{l}\text { Missing data or } \\
\text { not classifiable }\end{array} \\
\mathrm{N}=365\end{array}$} & \multirow{2}{*}{$\begin{array}{l}\text { Overall } \\
\mathrm{N}=1325\end{array}$} \\
\hline & & & & & \\
\hline \multicolumn{6}{|l|}{ CT findings } \\
\hline Normal CT* & $218(79.3 \%)$ & $423(80.6 \%)$ & $88(55.0 \%)$ & $241(66.0 \%)$ & $970(73.2 \%)$ \\
\hline Intracranial traumatic findings & $10(3.6 \%)$ & $36(6.9 \%)$ & $30(18.8 \%)$ & $7(1.9 \%)$ & $83(6.3 \%)$ \\
\hline Epidural hematoma & $1(0.4 \%)$ & $2(0.4 \%)$ & $4(2.5 \%)$ & $0(0 \%)$ & $7(0.5 \%)$ \\
\hline Subdural hematoma & $3(1.1 \%)$ & $12(2.3 \%)$ & $15(9,4 \%)$ & $1(0.3 \%)$ & $31(2.3 \%)$ \\
\hline $\mathrm{SAH} /$ intraventricular hemorrhage & $2(0.7 \%)$ & $12(2.3 \%)$ & $12(7.5 \%)$ & $3(0.8 \%)$ & $29(2.2 \%)$ \\
\hline Contusion hematoma & $4(1.5 \%)$ & $15(2.9 \%)$ & $17(10.6 \%)$ & $5(1.4 \%)$ & $41(3.1 \%)$ \\
\hline Diffuse cerebral edema & $1(0.4 \%)$ & $1(0.2 \%)$ & $5(3.1 \%)$ & $0(0 \%)$ & $7(0.5 \%)$ \\
\hline Pneumocephalus & $1(0.4 \%)$ & $8(1.5 \%)$ & $7(4.4 \%)$ & $0(0 \%)$ & $16(1.2 \%)$ \\
\hline Cranial fracture(s) & $4(1.5 \%)$ & $17(3.2 \%)$ & $12(7.5 \%)$ & $5(1.4 \%)$ & $38(2.9 \%)$ \\
\hline With impression & $1(0.4 \%)$ & $2(0.4 \%)$ & $2(1.3 \%)$ & $0(0 \%)$ & $5(0.4 \%)$ \\
\hline Without impression & $1(0.4 \%)$ & $7(1.3 \%)$ & $6(3.8 \%)$ & $3(0.8 \%)$ & $17(1.3 \%)$ \\
\hline Skull base fracture & $2(0.7 \%)$ & $10(1.9 \%)$ & $7(4.4 \%)$ & $2(0.5 \%)$ & $21(1.6 \%)$ \\
\hline Non-traumatic pathological findings & $45(16.4 \%)$ & $64(12.2 \%)$ & $44(27.5 \%)$ & $114(31.2 \%)$ & $267(20.2 \%)$ \\
\hline \multicolumn{6}{|l|}{ Admission to hospital } \\
\hline Number of admissions & $188(68.4 \%)$ & $285(54.3 \%)$ & $120(75.0 \%)$ & $196(53.7 \%)$ & $789(59.6 \%)$ \\
\hline Median length of stay (days) & 1.0 & 0.5 & 1.5 & 0.5 & 0.5 \\
\hline Range length of stay (days) & $0.0-52.0$ & $0.0-98.0$ & $0.0-108.0$ & $0.0-60.0$ & $0.0-108.0$ \\
\hline \multicolumn{6}{|l|}{ Admission to hospital due to: } \\
\hline Head injury alone & $30(10.9 \%)$ & $103(19.6 \%)$ & 37 (23.1\%) & $16(4.4 \%)$ & $186(14.0 \%)$ \\
\hline Other causes than injuries & $3(1.1 \%)$ & $7(1.3 \%)$ & $7(4.4 \%)$ & $68(18.6 \%)$ & $85(6.4 \%)$ \\
\hline Other injuries than the head injury & $86(31.3 \%)$ & $35(6.7 \%)$ & $6(3.8 \%)$ & $16(4.4 \%)$ & $143(10.8 \%)$ \\
\hline Combinations & $68(24.7 \%)$ & $140(26.7 \%)$ & $70(43.8 \%)$ & 95 (26.0\%) & $373(28.2 \%)$ \\
\hline Unknown cause/missing data & $1(0.4 \%)$ & $0(0 \%)$ & $0(0.0 \%)$ & $1(0.3 \%)$ & $2(0.2 \%)$ \\
\hline Not admitted & $87(31.6 \%)$ & $240(45.7 \%)$ & $40(25.0 \%)$ & 169 (46.3\%) & $536(40.5 \%)$ \\
\hline Neurosurgical intervention & $3(1.1 \%)$ & $1(0.2 \%)$ & $8(5.0 \%)$ & $0(0 \%)$ & $12(0.9 \%)$ \\
\hline Intracranial pressure monitoring & $0(0 \%)$ & $1(0.2 \%)$ & $4(2.5 \%)$ & $0(0 \%)$ & $5(0.4 \%)$ \\
\hline Reposition of cranial fracture(s) & $1(0.4 \%)$ & $0(0 \%)$ & $2(1.3 \%$ & $0(0 \%)$ & $3(0.2 \%)$ \\
\hline External ventricle drain & $0(0 \%)$ & $0(0 \%)$ & $0(0 \%)$ & $0(0 \%)$ & $0(0 \%)$ \\
\hline Craniotomy & $1(0.4 \%)$ & $0(0 \%)$ & $2(1.3 \%)$ & $0(0 \%)$ & $3(0.2 \%)$ \\
\hline Burr hole-procedure & $1(0.4 \%)$ & $0(0 \%)$ & $0(0 \%)$ & $0(0 \%)$ & $1(0.1 \%)$ \\
\hline In-house-mortality & $3(1.1 \%)$ & $1(0.2 \%)$ & $2(1.3 \%)$ & $8(2.2 \%)$ & $14(1.1 \%)$ \\
\hline
\end{tabular}

*Except extra-cranial hematoma or swelling.

$\S$ Evacuation of chronic subdural hematoma.

unnecessary CT scans, without compromising patient safety $[25,26]$. However, an earlier randomized controlled study showed that rates of CT imaging were not reduced [27], and they may even be increased after guideline implementation [28]. A recent study among $\mathrm{CT}$ ordering physicians report that "fear of missing a traumatic intracranial lesion" may explain many "unnecessary CT scans", despite knowledge about management guidelines [29]. As seen in our study, compliance with guidelines is far from perfect, and over triage with unnecessary CT was observed in more than half of the classifiable minimal injuries. Hypothetical health economic analyses that assume that guidelines are or can be followed may therefore be overly optimistic and simplified.

\section{Time of assessment and external validity}

We recorded the clinical information obtained before the CT examination in this study. However, as an indication of the dynamics in such patient evaluations, we 
Table 6 Compliance with Scandinavian guidelines for minimal, mild and moderate head injuries

\begin{tabular}{|c|c|c|c|c|c|}
\hline \multirow[t]{2}{*}{ Compliance to Scandinavian guidelines } & \multirow{2}{*}{$\begin{array}{l}\text { Minimal injury } \\
\mathrm{N}=275\end{array}$} & \multirow{2}{*}{$\begin{array}{l}\text { Mild injury } \\
\mathrm{N}=525\end{array}$} & \multirow{2}{*}{$\begin{array}{l}\text { Moderate injury } \\
\mathrm{N}=160\end{array}$} & \multirow{2}{*}{$\begin{array}{l}\text { Missing data or } \\
\text { not classifiable } \\
\mathrm{N}=365\end{array}$} & \multirow{2}{*}{$\begin{array}{l}\text { Overall } \\
\mathrm{N}=1325\end{array}$} \\
\hline & & & & & \\
\hline \multicolumn{6}{|l|}{ Compliance with $C T$ recommendation } \\
\hline Yes & $126(45.8 \%)$ & $525(100 \%)$ & 160 (100\%) & $78(21.4 \%)$ & $889(67.1 \%)$ \\
\hline No & $149(54.2 \%)$ & $0(0 \%)$ & $0(0 \%)$ & $0(0 \%)$ & $149(11.2 \%)$ \\
\hline Impossible to assess & $0(0 \%)$ & $0(0 \%)$ & $0(0 \%)$ & $287(78.6 \%)$ & $287(21.7 \%)$ \\
\hline \multicolumn{6}{|l|}{ Compliance with admittance recommendation } \\
\hline \multicolumn{6}{|l|}{ Yes } \\
\hline No & $102(37.1 \%)$ & $290(55.2 \%)$ & $82(51.2 \%)$ & $120(32.9 \%)$ & $594(44.8 \%)$ \\
\hline Impossible to assess or admitted due & $16(5.8 \%)$ & $68(13.0 \%)$ & $25(15.6 \%)$ & $9(2.5 \%)$ & $118(8.9 \%)$ \\
\hline to other reasons than head injury & $157(57.1 \%)$ & $167(31.8 \%)$ & $53(33.1 \%)$ & $236(64.7 \%)$ & $613(46.3 \%)$ \\
\hline \multicolumn{6}{|l|}{$\begin{array}{l}\text { Compliance with both } C T \text { and } \\
\text { admittance recommendations }\end{array}$} \\
\hline \multicolumn{6}{|l|}{ Yes } \\
\hline No & $12(4.4 \%)$ & $289(55.0 \%)$ & $81(50.6 \%)$ & $31(8.5 \%)$ & $413(31.2 \%)$ \\
\hline Impossible to assess & 152 (55.3\%) & 69 (13.1\%) & $26(16.2 \%)$ & $9(2.5 \%)$ & 256 (19.3\%) \\
\hline
\end{tabular}

found that $25 \%$ of patients that before CT were assumed to have moderate head injuries were not even admitted to hospital. Risk stratification and recommendations in most management guidelines, is usually based on the clinical situation at one point of time. Clinical evaluation of a head injury patient is nevertheless a continuous process based on the anamnestic information available from the time of injury along with history or observations of improvements or deteriorations over time, before and after seeking medical attention. Anamnestic information, witness information, symptoms and level of consciousness will change, and most often improve over time.

Our findings are based on the review of CT examinations in a Norwegian university hospital with a neurosurgical department. These findings may therefore not directly be extrapolated to other, patient selections, regions, countries, health care systems, or treatment guidelines. Even so, the frequent inability to apply management guidelines directly due to missing key information is probably a universal problem that has received little attention.

\section{Study strengths and limitations}

The prospective and rigid questionnaire-based evaluation of physicians' diagnostic considerations prior to ordering CT scans, the unselected consecutive patient population, along with the magnitude of this study makes it among the most rigorous effort to date to evaluate head injury guideline compliance in everyday clinical practice. Inclusion was nevertheless based only on patients who underwent $\mathrm{CT}$ examinations. We have therefore no information on under triage with $\mathrm{CT}$, i.e. direct discharge without $\mathrm{CT}$ examination.

To ideally study compliance with and performance of management guidelines, at least two prospective study points would be preferable; one before CT scans, and one at admittance or discharge from hospital. This could probably increase the compliance in the group of assumed moderate injury in this study, since most of

Table 7 Possible predictor variables associated with non-assessable guidline compliance

\begin{tabular}{|c|c|c|c|c|c|c|}
\hline Variables in the regression model & Unadjusted Odds ratio & $95 \% \mathrm{Cl}$ & p-value & Adjusted Odds ratio & $95 \% \mathrm{Cl}$ & p-value \\
\hline Age $<4$ years & 3.1 & 1.4 to 7.1 & 0.006 & 25.6 & 9.1 to 72.0 & $<0.001$ \\
\hline Age $\geq 65$ years & 2.7 & 2.0 to 3.6 & $<0.001$ & 1.8 & 0.8 to 4.4 & 0.180 \\
\hline Gender : female & 1.7 & 1.3 to 2.2 & $<0.001$ & 1.2 & 0.6 to 2.1 & 0.654 \\
\hline Suspicion of alcohol/drug influence & 0.4 & 0.3 to 0.8 & 0.003 & 0.8 & 0.3 to 1.9 & 0.602 \\
\hline Severe headache, nausea or vomiting & 1.9 & 1.4 to 2.5 & $<0.001$ & 2.1 & 1.1 to 4.0 & 0.034 \\
\hline Possible medical cause of injury* & 41.3 & 24.2 to 70.5 & $<0.001$ & 234.6 & 108.5 to 507.3 & $<0.001$ \\
\hline Use of anti-platelet drugs, e.g. acetylsalicylic acid & 3.4 & 2.2 to 5.0 & $<0.0 \mid 01$ & 2.5 & 1.0 to 6.5 & 0.052 \\
\hline Non-traumatic CT findings & 2.3 & 1.7 to 3.1 & $<0.001$ & 3.3 & 1.5 to 7.3 & 0.003 \\
\hline
\end{tabular}

*Such as syncope, epilepsy, cardiac arrest etc. 
them would have been reclassified to the mild, and some even to the minimal group. Our study also suffered from the inability to stratify all patients into the risk groups according to HISS. This is partial a response-rate problem, but also reflects the challenge of categorizing heterogeneous trauma patients in a dynamic state with frequent confounding factors and limited anamnestic and clinical information available.

\section{Conclusions}

Despite the prospective study design, guideline compliance was not assessable in half of the patients. Important key variables for guideline based decision making were often not obtainable at the time of CT referral, and admission due to the head injury alone was quite uncommon. Definite compliance with guidelines was observed in only about one third of all patients and over triage with CT scan was observed in more than half of minimal injuries. The factors of importance for risk stratification according to guidelines were most often difficult to assess in infants/toddlers, in patients with possible medical cause of injuries, severe headache/nausea or vomiting and the presence of non-traumatic CT findings. We still believe that decision rules can be an important clinical support in many cases and can ensure a framework for common practice with minimal risks of under triage. However, the frequent challenge with non-obtainable key clinical variables should be considered when updating guidelines.

\section{Competing interests}

The authors declare that they have no competing interests.

\section{Authors' contributions}

HIS participated in the design of the study, collected the data and performed statistical analyses. OS performed the statistical analyses and drafted the manuscript. KGM performed statistical analyses, made figures and helped to draft the manuscript. AV participated in the design of the study, and helped to draft the manuscript. All authors read and approved the final manuscript.

\section{Author details}

'Department of Radiology and Diagnostic Imaging, St.Olavs University Hospital, Trondheim N-7006, Norway. ${ }^{2}$ Department of Neurosurgery, St.Olavs University Hospital, Trondheim N-7006, Norway. ${ }^{3}$ MI-Lab, Department of Circulation and Medical Imaging, Norwegian University of Science and Technology, Trondheim N-7006, Norway. ${ }^{4}$ Department of Neuroscience, Norwegian University of Science and Technology, Trondheim N-7006, Norway.

Received: 10 April 2012 Accepted: 28 August 2012

Published: 4 September 2012

\section{References}

1. Stiell IG, Wells GA, Vandemheen K, Clement C, Lesiuk H, Laupacis A, McKnight RD, Verbeek R, Brison R, Cass D, Eisenhauer ME, Greenberg G, Worthington J: The Canadian CT Head Rule for patients with minor head injury. Lancet 2001, 357:1391-1396.

2. Haydel MJ, Preston CA, Mills TJ, Luber S, Blaudeau E, DeBlieux PM: Indications for computed tomography in patients with minor head injury. N Engl J Med 2000, 343:100-105.
3. Servadei F, Teasdale G, Merry G: Defining acute mild head injury in adults: a proposal based on prognostic factors, diagnosis, and management. J Neurotrauma 2001, 18:657-664.

4. Vos PE, Battistin L, Birbamer G, Gerstenbrand F, Potapov A, Prevec T, Stepan Ch A, Traubner P, Twijnstra A, Vecsei L, von Wild K: EFNS guideline on mild traumatic brain injury: report of an EFNS task force. Eur J Neurol 2002, 9:207-219.

5. Ingebrigtsen T, Romner B, Kock-Jensen C: Scandinavian guidelines for initial management of minimal, mild, and moderate head injuries. The Scandinavian Neurotrauma Committee. J Trauma 2000, 48:760-766.

6. Harnan SE, Pickering A, Pandor A, Goodacre SW: Clinical decision rules for adults with minor head injury: a systematic review. J Trauma 2011, 71:245-251.

7. Heskestad B, Baardsen R, Helseth E, Ingebrigtsen T: Guideline compliance in management of minimal, mild, and moderate head injury: high frequency of noncompliance among individual physicians despite strong guideline support from clinical leaders. J Trauma 2008, 65:1309-1313.

8. Harad FT, Kerstein MD: Inadequacy of bedside clinical indicators in identifying significant intracranial injury in trauma patients. J Trauma 1992, 32:359-361. discussion 361-353.

9. Mooney JS, Yates A, Sellar L, Shipway T, Roberts C, Parris R, Hassan Z, Thomas M, Smith M, Lecky F: Emergency head injury imaging: implementing NICE 2007 in a tertiary neurosciences centre and a busy district general hospital. Emerg Med J 2011, 28:778-782.

10. Soreide K, Reite A: Evaluating compliance to the Scandinavian guidelines on mild head injury. J Trauma 2009, 67:217-218.

11. Stein SC, Spettell C: The Head Injury Severity Scale (HISS): a practical classification of closed-head injury. Brain Inj 1995, 9:437-444.

12. Harr ME, Heskestad B, Ingebrigtsen T, Romner B, Ronning P, Helseth E: Alcohol consumption, blood alcohol concentration level and guideline compliance in hospital referred patients with minimal, mild and moderate head injuries. Scand I Trauma Resusc Emerg Med 2011, 19:25.

13. Stein SC, Fabbri A, Servadei F, Glick HA: A critical comparison of clinical decision instruments for computed tomographic scanning in mild closed traumatic brain injury in adolescents and adults. Ann Emerg Med 2009, 53:180-188.

14. Pandor A, Goodacre S, Harnan S, Holmes M, Pickering A, Fitzgerald P, Rees A, Stevenson M: Diagnostic management strategies for adults and children with minor head injury: a systematic review and an economic evaluation. Health Technol Assess 2011, 15:1-202.

15. Livingston $D H$, Loder PA, Hunt CD: Minimal head injury: is admission necessary? Am Surg 1991, 57:14-17.

16. Livingston DH, Loder PA, Koziol J, Hunt CD: The use of CT scanning to triage patients requiring admission following minimal head injury. J Trauma 1991, 31:483-487. discussion 487-489.

17. Shackford SR, Wald SL, Ross SE, Cogbill TH, Hoyt DB, Morris JA, Mucha PA, Pachter HL, Sugerman HJ, O'Malley K, et al: The clinical utility of computed tomographic scanning and neurologic examination in the management of patients with minor head injuries. J Trauma 1992, 33:385-394.

18. Stein SC, RosS SE: Mild head injury: a plea for routine early CT scanning. J Trauma 1992, 33:11-13.

19. Feuerman T, Wackym PA, Gade GF, Becker DP: Value of skull radiography, head computed tomographic scanning, and admission for observation in cases of minor head injury. Neurosurgery 1988, 22:449-453.

20. Mohanty SK, Thompson W, Rakower S: Are CT scans for head injury patients always necessary? J Trauma 1991, 31:801-804. discussion 804-805.

21. Ingebrigtsen T, Romner B: Management of minor head injuries in hospitals in Norway. Acta Neurol Scand 1997, 95:51-55.

22. Stiell IG, Wells GA, Vandemheen K, Laupacis A, Brison R, Eisenhauer MA, Greenberg GH, MacPhail I, McKnight RD, Reardon M, Verbeek R, Worthington J, Lesiuk H: Variation in ED use of computed tomography for patients with minor head injury. Ann Emerg Med 1997, 30:14-22.

23. af Geijerstam JL, Oredsson S, Britton M: Medical outcome after immediate computed tomography or admission for observation in patients with mild head injury: randomised controlled trial. BMJ 2006, 333:465.

24. Holmes MW, Goodacre S, Stevenson MD, Pandor A, Pickering A: The costeffectiveness of diagnostic management strategies for adults with minor head injury. Injury 2012, 43:1423-1431.

25. Smits M, Dippel DW, de Haan GG, Dekker HM, Vos PE, Kool DR, Nederkoorn PJ, Hofman PA, Twijnstra A, Tanghe HL, Hunink MG: External validation of the 
Canadian CT Head Rule and the New Orleans Criteria for CT scanning in patients with minor head injury. JAMA 2005,

294:1519-1525.

26. Smits M, Dippel DW, Steyerberg EW, de Haan GG, Dekker HM, Vos PE, Kool DR, Nederkoorn PJ, Hofman PA, Twijnstra A, Tanghe HL, Hunink MG:

Predicting intracranial traumatic findings on computed tomography in patients with minor head injury: the CHIP prediction rule. Ann Intern Med 2007, 146:397-405.

27. Stiell IG, Clement CM, Grimshaw JM, Brison RJ, Rowe BH, Lee JS, Shah A, Brehaut J, Holroyd BR, Schull MJ, McKnight RD, Eisenhauer MA, Dreyer J, Letovsky E, Rutledge T, Macphail I, Ross S, Perry JJ, Ip U, Lesiuk H, Bennett C, Wells GA: A prospective cluster-randomized trial to implement the Canadian CT Head Rule in emergency departments. CMAJ 2010, 182:1527-1532.

28. Fong C, Chong W, Villaneuva E, Segal AY: Implementation of a guideline for computed tomography head imaging in head injury: a prospective study. EMA 2008, 20:410-419.

29. Rohacek M, Albrecht M, Kleim B, Zimmermann H, Exadaktylos A: Reasons for ordering computed tomography scans of the head in patients with minor brain injury. Injury 2012, 43:1415-1418.

doi:10.1186/1757-7241-20-62

Cite this article as: Strand et al:: Evaluation of the Scandinavian guidelines for head injuries based on a consecutive series with computed tomography from a Norwegian university hospital. Scandinavian Journal of Trauma, Resuscitation and Emergency Medicine 2012 $20: 62$.

\section{Submit your next manuscript to BioMed Central and take full advantage of:}

- Convenient online submission

- Thorough peer review

- No space constraints or color figure charges

- Immediate publication on acceptance

- Inclusion in PubMed, CAS, Scopus and Google Scholar

- Research which is freely available for redistribution 